\title{
Reducing Your Risk for Diabetes: A Resource Guide ${ }^{1}$
}

\author{
Linda B. Bobroff ${ }^{2}$
}

The number of people with diabetes is rising at an alarming rate in the US, as it is worldwide. Persons with "prediabetes" have elevated blood glucose (sugar), but their levels are not high enough for a diagnosis of diabetes. If you have prediabetes, you are at increased risk for developing diabetes.

The two tests most commonly used to determine if you are at risk for diabetes are the fasting plasma glucose (FPG) test and the hemoglobin A1C test. The FPG test measures glucose in the plasma (the liquid part of blood) at a specific point in time. The A1C test is an indicator of average blood glucose levels over the previous two to three months. Table 1 shows the values for each test that are normal and that indicate prediabetes and diabetes.

All adults should have their blood glucose checked on a regular basis. This will allow people diagnosed with diabetes to begin treatment early. The key to preventing or forestalling the severe health complications of this disease is early diagnosis and treatment. Research has shown that people with prediabetes can significantly reduce their risk of getting diabetes through lifestyle changes. Eating a healthful diet and being physically active are the keys to a healthier lifestyle. These changes can help people with prediabetes lose weight and lower their blood glucose. For a 200 -pound person, losing as few as 10 pounds (5\% of body weight) significantly reduces risk for diabetes.

Many free resources are available to help people of all backgrounds lead healthier lives and reduce their risk for diabetes. Here are some resources to choose from to help you and your family members begin taking steps to improve your health.

\section{National Diabetes Education Program}

The following materials from the National Diabetes Education Program (NDEP) are available at 1-800-860-8747, or from their website: http://www.ndep.nih.gov/publications/ index.aspx?Keyword=Prevention $2 \&$ Go. $x=17 \&$ Go.y $=13$. The Centers for Disease Control and Prevention (CDC) also has materials focused on diabetes prevention: https://www.cdc. gov/diabetes/ndep/index.html.

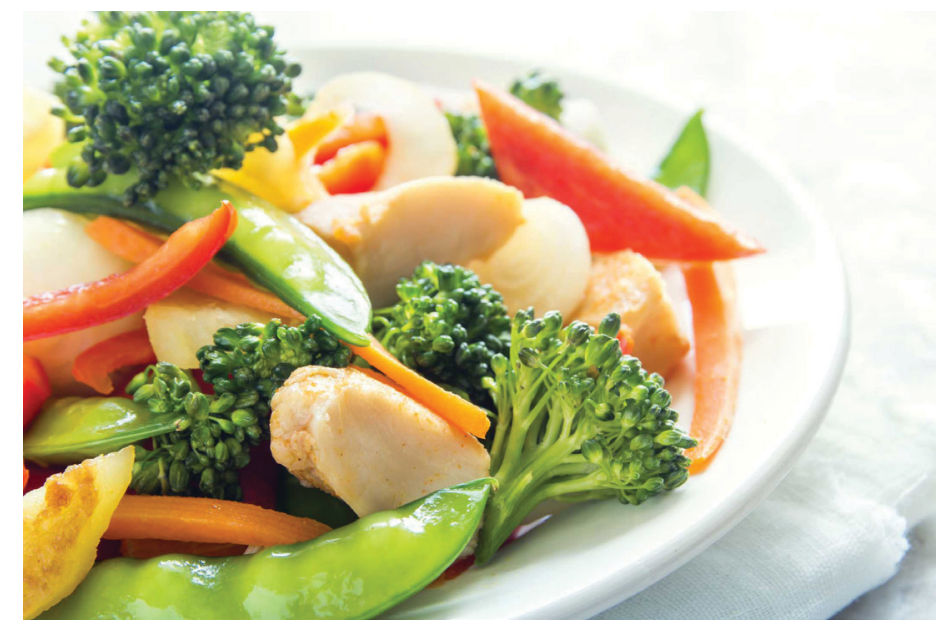

Figure 1. Eating a diet rich in protein, vegetables, legumes, and other healthy foods in amounts that promote a healthy weight helps reduce risk for diabetes.

Credits: Mizina / iStock / Getty Images Plus

1. This document is FCS8840, one of a series of the Department of Family, Youth and Community Sciences, UF/IFAS Extension. Original publication date May 2007. Revised February 2018. Visit the EDIS website at http://edis.ifas.ufl.edu.

2. Linda B. Bobroff, PhD, RDN, professor, Department of Family, Youth and Community Sciences; UF/IFAS Extension, Gainesville, FL 32611.

The Institute of Food and Agricultural Sciences (IFAS) is an Equal Opportunity Institution authorized to provide research, educational information and other services only to individuals and institutions that function with non-discrimination with respect to race, creed, color, religion, age, disability, sex, sexual orientation, marital status, national origin, political opinions or affiliations. For more information on obtaining other UF/IFAS Extension publications, contact your county's UF/IFAS Extension office. 
The NDEP has developed a series of tip sheets to help people of all ages prevent diabetes. One tip sheet (Two Reasons I Find Time to Prevent Diabetes: My Future and Theirs) is available in English and 15 languages targeting Asian Americans and Pacific Islanders: https://www.niddk. nih.gov/health-information/diabetes/overview/preventingtype-2-diabetes/two-reasons .

Another tip sheet, Choose More than 50 Ways to Prevent Type 2 Diabetes, focuses mainly on what and how much you eat, and how to increase your physical activity. Included is a link to a booklet to help you keep track of your food intake and your activity level. https://www. niddk.nih.gov/health-information/diabetes/overview/ preventing-type-2-diabetes/50-ways.

\section{Your Game Plan to Prevent Type 2 Diabetes}

Your Game Plan to Prevent Type 2 Diabetes provides ideas and resources, including videos, to help you get started in taking small steps to improve your lifestyle and reduce your diabetes risk. Your Game Plan is at this link: https:// www.niddk.nih.gov/health-information/diabetes/overview/ preventing-type-2-diabetes/game-plan.

\section{Movimiento Por Su Vida}

A brief YouTube music video, Movimiento Por Su Vida, from the NDEP is available at https://www.youtube.com/ watch? $=$ ohkY8OHYwGA to get you motivated, and this five-minute podcast from the CDC is a brief introduction to the Movimiento Por Su Vida music: https://www2c.cdc. gov/podcasts/player.asp?f=7228.

\section{Other Resources}

\section{MyPlate}

MyPlate is the food guide icon introduced by the USDA in 2011. The ChooseMyPlate website offers a wealth of information about healthy eating, which, along with physical activity, is a cornerstone of diabetes prevention. Visit http:// www.choosemyplate.gov and design an eating and physical activity plan that's right for you.

\section{Are you at risk?}

The American Diabetes Association website offers information related to nutrition and fitness, as well as selfassessment tools, including a diabetes risk calculator: http:// www.diabetes.org/are-you-at-risk/my-health-advisor/

\section{Food and Fitness}

This section on the American Diabetes Association website provides information about food and meal planning, as well as recipes to promote healthy living for diabetes prevention: http://www.diabetes.org/food-and-fitness/

\section{Diabetes and Me}

The Centers for Disease Control and Prevention (CDC) website offers detailed information about prediabetes, a variety of materials related to diabetes prevention, and links to other resources: https://www.cdc.gov/diabetes/basics/ prediabetes.html

\section{Solutions for Your Life}

This is the UF/IFAS Extension website. For information on nutrition, healthy lifestyles, diabetes, and other health issues, begin your search in the Health \& Nutrition section: http://solutionsforyourlife.ufl.edu/ families_and_consumers/health_and_nutrition/

\section{American Diabetes Association Bookstore}

For additional resources, you can check out the American Diabetes Association online bookstore. It offers a variety of books about diabetes, including cookbooks and meal planning guides, for consumers and professionals. Gift of Hope items support diabetes research: http://store.diabetes. org/?WTLPromo=prev_bookstore\&vms=213264860505

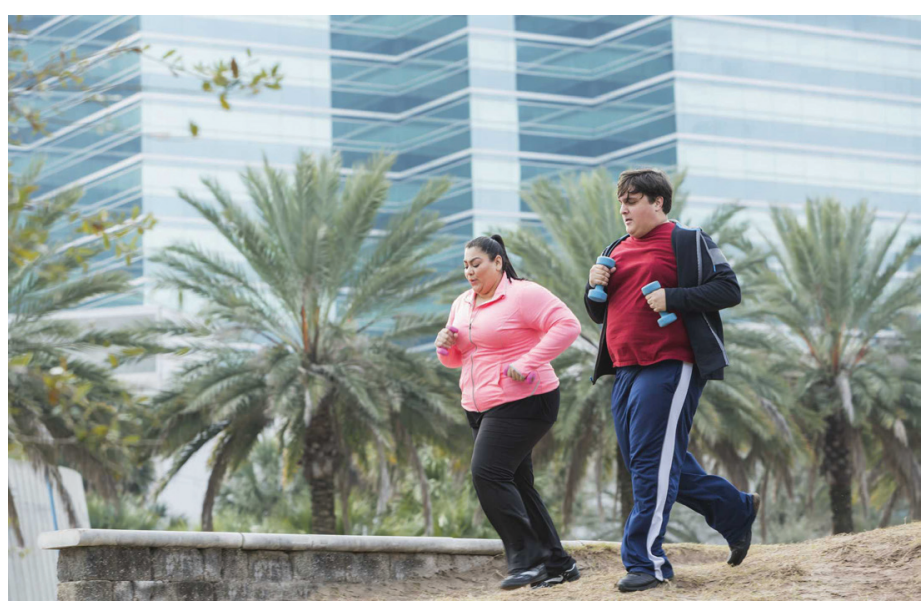

Figure 2. If you are at risk for diabetes, lifestyle changes, such as becoming more physically active, can help prevent the disease. Credits: kali9/Gettyimages 
Table 1. Sample test results for the two tests commonly used to determine risk for diabetes.

\begin{tabular}{|l|c|c|}
\hline & Fasting Plasma Glucose mg/dl* & $\begin{array}{c}\text { Hemoglobin A1C } \\
\%\end{array}$ \\
\hline Normal & Less than 100 & Less than 5.7 \\
\hline Prediabetes & $100-125$ & $5.7-6.4$ \\
\hline Diabetes & 126 or higher & 6.5 or higher \\
\hline${ }^{*} \mathrm{mg} / \mathrm{dl}=$ milligrams of glucose per deciliter (100 milliliters) of blood. & \\
\hline
\end{tabular}

